\title{
Students' Entry Qualification and Academic Performance in Basic Schools of Nursing in Enugu State between 1995 and 1999
}

\author{
Ngozi P. Ogbonnaya', Perpetua 0. U. Okpuruka' ${ }^{2}$, Peace N. Iheanacho', Afam $\mathrm{Ndu}^{3}$ \\ ${ }^{1}$ Department of Nursing Sciences, University of Nigeria, Enugu Campus, Enugu, Nigeria \\ ${ }^{2}$ University of Port Harcourt, Teaching Hospital, Port Harcourt, Nigeria \\ ${ }^{3}$ School of Psychiatric and Mental Health Nursing, Federal Neuropsychaitric Hospital, Enugu, Nigeria \\ Email: afamci@yahoo.com
}

Received 5 November 2013; revised 20 December 2013; accepted 5 January 2014

Copyright (C) 2014 by authors and Scientific Research Publishing Inc.

This work is licensed under the Creative Commons Attribution International License (CC BY).

http://creativecommons.org/licenses/by/4.0/

c) (i) Open Access

\section{Abstract}

This study was a descriptive study of the correlation type, carried out to find out the relationship between entry qualification and academic performance in two basic schools of nursing in Enugu State, South-East, Nigeria, between 1995 and 1999. The study retrospectively examined the scores of a sample of 390 nursing students. Data were 0' level GCE/SSCE Grades, representing the entry qualification; and the final pre-qualifying examination result scores, representing the final academic performance collected from student records and analyzed based on the formulated hypotheses. Pearson's product-moment Coefficient of Correlation and t-test were used to compare performances. A positive correlation which was statistically significant was found between entry qualifications and final performance. One of the schools performed better than the other, while sciencebased students performed better than non-science-based students. It was recommended that relevant regulatory bodies should ensure that prospective student nurses get credit passes in all the basic sciences as part of the requirements for admission.

\section{Keywords}

Academic Performance, Entry Qualification, Schools of Nursing

\section{Introduction and Background}

The first set of nursing students, in Nigeria, were people who had worked as domestic servants for expatriate missionaries. Nursing was therefore looked down on because nurses were seen as illiterates or half-baked pro- 
fessionals. The establishment of the Nursing Council of Nigeria through the Nurses Ordinance of 1947 was the first major step toward the regulation of Nursing Training in Nigeria (Igbinosun, 1996). When the School of Nursing University College Hospital (UCH) Ibadan was opened, the requirements for entry to the School became Secondary Education with a passing grade in five subjects including English language and one Science subject. However, a majority of the schools, mainly mission-based schools did not follow this recommendation and for many years still admitted students with less than the 5 credit passes generally accepted for tertiary education in the country. However, Teaching Hospitals Schools of Nursing maintained the entry requirements. Today some Nigerian universities have opened Departments of Nursing Sciences that have also stipulated entry requirements of 5 credit passes including the basic science subjects i.e. Biology, Chemistry and Physics, plus English Language and Mathematics. In its efforts to strengthen nursing education in Nigeria, the Nursing and Midwifery Council of Nigeria mapped out a National Diploma/Higher National Diploma (ND/HND) Nursing Programme in which admission should be through Poly-Joint Admission Matriculation Board Examination (Sensitization/Implementation Workshop for ND/HND Nursing Programme, 2002).

Education is crucial to the development of any profession. The need to produce nurses capable of functioning as quality practitioners in the health care field is irreplaceable, the necessity becoming more obvious with increasing cost of health care, increasing inflation and economic meltdown in both developed and developing countries. Sophisticated advances in medical sciences and technology, increasing awareness in the populace and the overall increase in available knowledge through the internet have also increased the expectations of the public for quality care and demand for their rights.

One of the most basic and reasonable things done in producing qualitative nurses is to begin by selecting right candidates as far as entry qualifications are concerned.

\section{Statement of Problem}

Educationists from different disciplines have always considered the background of the learners in the preparation of curricula and before every classroom instruction. The background of the learner is necessary for the formulation of educational objectives, which are what the learners are expected to achieve at the end of the course. Nursing education, retention, and completion rates are a global concern (Glossop, 2001). Nursing schools are faced with the burden of increasing the number of graduating students while at the same time ensuring that new graduates are competent to function in the ever-changing health care environment. Health care facilities are quite challenging to the health care provider today with an increase in the number and needs of patients, sophisticated technology, and complicated drug regimens. The rigors of the healthcare profession require that professionals have a strong background in science (Griffiths, Bevil, O’Connor, \& Wieland, 1995). Retention of nursing students and successful completion of academic and professional programme are complex issues that may involve a variety of academic and non-academic factors due to the fact that nursing programs have recruited from a diverse population group in terms of age and academic ability (Mckenzie, 2008). The UK has attempted to adopt a procedure for selecting nursing students in order to increase retention and completion rates. Canada has already put a selection procedure in place that has been quite successful (Glossop, 2001). A review of the literature revealed that numerous studies have been conducted regarding nursing student performance. The majority of these studies were limited to performance on the National Council Licensure Examination for Registered Nurses (NCLEX-RN) in the USA and involved students in education programmes at the baccalaureate level. A common theme among all of these studies was the need for early identification and intervention with students considered at-risk for academic difficulties (Alexanders \& Brophy, 1997; Croxon \& Maginnis, 2006; Habley \& McClanahan, 2004; Hossler, 2005; Ramsburg, 2007). Success on the NCLEX-RN is of great concern to colleges as graduates of nursing programmes are not eligible to practice until successful completion (Fowles, 1992). The same is true of Nigeria.

In Nigeria, until recently, the only mode of entry into nursing is the three-year professional certificate programme from which students graduate after sitting for the professional licensing examination. Students are permitted to re-write this examination two more times before unsuccessful candidates are asked to withdraw from the programme with no form of certification. Recently, however, universities have started opening departments of Nursing Sciences, for the Baccalaureate degree in nursing in the course of which students also sit for the professional qualifying examination. Complaints are, however, rife from nurse educators, examiners and the regulatory agency about the poor performance of the students in the final qualifying/licensure examination. Many 
factors could be responsible for this, one of which could be the basic preparation of these students as represented by their certificates in the Senior School Certificate Examination (SSCE) or its equivalent. However, very little research has been conducted on nursing students' academic performance in relation to their entry qualifications in the local setting.

In Nigeria, the SSCE certificate from the West African Examination Council (WAEC), or its equivalent from the National Examination Council (NECO), the WAEC Ordinary Level General Certificate of Education (O' level GCE), or the one from the National Board for Technical Education (NABTEB), are the accepted entry requirements to any tertiary education in the country. A student who was able to obtain at least credit passes in at least five subjects (which includes English Language and Mathematics, and 3 other subjects as relevant to one's field of interest) in not more than two sittings is deemed to have the aptitude to cope with the demands of tertiary education. The converse also applies. It is on this premise that the researchers embarked on the present study to find the relationship between entry qualification and performance of student nurses in the basic schools of nursing in Enugu State.

\section{Objectives of the Study}

Based on the purpose, the following objectives have been drawn to:

1) Identify the relationship between students entry qualification and students academic performance at the end of the programme.

2) Determine the difference in the academic performance of the students who have credit passes in all the basic sciences subjects and the students who do not have credit passes in all the basic science subjects at the end of the progamme.

3) Find out the difference between the academe performances of the students in the schools used for the study.

\section{Significance of the Study}

Successful establishment of relationship between entry qualification and students performance will provide information that will help decision-makers and educationists in the nursing profession in predicting performance and therefore proper selection of prospective students into the schools of nursing. This will in turn help in producing quality nurses that will meet the health needs of the society.

\section{Definition of Terms}

Entry qualification is the prerequisite for entry into school of nursing. Here it is five credit passes, including: Biology/Health Science, English Language, and one Sciences Subject, taken from Physics, Mathematics and Chemistry, plus two other subjects in SSCE, GCE O' Level, etc. (Some Schools do not accept health Sciences for Biology). The grades in the 5 subjects, ranging from A1 to F9 were converted to scores from 9 to 1, with A1 scoring highest. From this a total entry qualification score was derived for each student.

Performance: In this study, the academic performance is represented by the average mark, made by the students in the pre-qualifying final examination. The average score from the three papers taken in the examination was computed.

\section{Literature Review}

Having students that graduate with flying colours is the aim of every institution. Graduation qualification which is the product of the institution's education process however has been said to depend not only on the learning process in the particular institution itself but also on the quality of input i.e., the quality of undergraduate students. Quality of students' intakes is one of the factors that contribute to quality of graduates (Alias \& Zain, 2006).

Entry qualifications are those prerequisites that qualify a student to enter into any school. Details of entry requirement vary from institution to institution in addition to the basic national prescription.

Faculty and administrators in higher education have judged good entry qualification as a criterion for students' admission, continuance and graduation within an institution (Kasworm \& Pike, 1994). A student's grades on entry are probably the single most revealing indicator of his or her successful adjustment to the intellectual demands of a particular college's course of study. Student's cognitive entry qualification which is believed to re- 
flect student's intelligence is a factor that determines student academic performance (Durotolu, 1994). Entry requirements determine a student's educational readiness and progress. In order to obtain or identify the student's background, strengths and weaknesses in a lesson or course of study, a process of tests, interviews and observations are carried out. After this, one would then be able to determine gap or differences between what the learner is at the point of entry and what he/she is expected to be at the completion of the specified course of study. The identified gap in what (Tyler, (1949)) saw as "needs". Need is this context is the gap between what is and what should be. The identified needs help to determine educational objectives. Educational objectives are what the students are expected to achieve at the end of the educational programme.

Entry qualification into schools of nursing include: an entrance examination which the student must pass after he/she must have obtained the WASC or its equivalent. Durotolu, (1994), states that academic performance is an expression used to represent student's scholastic standing. While Kasworm \& Pike, (1994), state that academic performance is cumulative grade-point average. Academic performance is synonymous with academic achievement and this means what a student has learned from instruction. It is an aspect of one's ability.

In many institutions, grades determine if a student will graduate. It also influences entry into high-level occupations, and influences admission into graduate/professional schools. Most large enterprises and companies these days also employ only those who made very high grades like first class and second class upper division.

Academic performance is measured with both scholastic aptitude test and achievement test. Scholastic aptitude is the capacity to do well in academic pursuits after a period of training. It predicts future performance from the present state of the individual. Examples include the Federal Ministry of Education Aptitude Test, the Joint Admission and Matriculation Board (JAMB) in Nigeria, etc. Achievement tests measure an individual's performance after undergoing a specified course of instruction. They represent what a person has learned, whereas aptitude test attempts to indicate what a person could learn. Examples of achievement tests are: End of course achievement tests, formative achievement test, general ability test, teacher-made achievement test, and of course the final secondary school education grade enshrined in the SSCE/GCE O' Level/NECO results in Nigeria.

Educational measurement and evaluation is an integral aspect of teaching and learning. It involves selection of measuring instruments, test construction, test administration and the use of, and interpretation of both teachermade and standardized tests. Testing, examination, measurement and evolution are terms used in teaching and learning. Testing involves the use of specific instrument to determine certain qualities or traits. Examination is broader and covers more topics than testing. Measurement on the other hand is the process by which things are differentiated by assigning a position (in figures) on a scale (a linear continuum) along which objects or integers to entities, attributes or events according to a specified rule.

Evaluation in education is the process of judging the effectiveness of educational experiences through careful appraisal. Gbamanja, (1991), is of the view that education is a process which seeks to change the behavior of students while evaluation is a process by which we find out whether the change in behaviour has occurred.

In nursing, evaluation is an integral part of care. The essence of nursing requires the nurse to evaluate constantly the patients' nursing needs as well as his/her own activities in meeting those needs. The nurse guides the patient to evaluate his health needs, determines how well he/she (the nurse) is meeting then and plans on how to maintain an optimal level of health.

Generally speaking, predicting future academic performance from past achievement as represented by present performance is not very easy. Most researchers have agreed that high school rank is the best single predictor of college success (Lengacher \& Keller, 1990).

Durotolu, (1994), studied the relationship between entry qualifications, (JAMB inclusive) combined with the various periodic course assessments and performance of students of college of education, ORO, at the end of the semester. The results show that both entry qualification and course tests, more or less, have significant influence on students' performance with course test showing a strong prodictive power.

Jimoh \& Durotolu, (1998), compared the entry qualification of NCE students with their performance in education course, considering WASC/GCE, Grade 11 Teachers' Certificate and Pivotal Certificate as entry qualification. They concluded that none of these three categories of students showed any significant superiority or otherwise over the other in education and teaching practice.

Platt et al. (2001) investigated preadmission criteria, Scholastic Aptitude Test (SAT) scores, and high school grade point average (HSGPA) and to determine the ability of those criteria to predict the college grade point average (CGPA) of graduates from programmes in athletic training and 5 other allied health disciplines. It was found from this study that overall, HSGPA and SATV score were predictive of student success (CGPA) in the 
allied health group as a whole and should continue to be used as part of the process of admission in higher education until such time that more predictive criteria are determined. The HSGPA was predictive of CGPA $\left(r^{2}=\right.$ 0.38 ) in athletic training graduates, predicting more than one third of the professional program success.

Dienye, (1991), studied the effect of entry qualification on teachers' performance at an in-service course in the institute of education, University of Port Harcourt. Nigeria. He used HND and Degree students and found that there was significant difference between the HND and degree certificate holders. He concluded that the degree holders were consistently better in their performance.

Abdulahi, (1983), correlated JAMB scores in physics, chemistry and economics; and first year university examination results. The result revealed a significant correlation with University scores in the same subjects while JAMB scores in Biology and Geography showed no significant correlation with the University scores.

McKenzie (2008) did a study on Predictors of Academic Success in a Career-Ladder Nursing programme at Hocking College. The result shows that the overall model was 92.7\% accurate in predicting academic success in the nursing programme. Variables that were significant included math assessment test scores, age, GPA in anatomy and physiology, GPA in psychosocial courses, and GPA in pharmacology courses. From the results she it appears that a strong background in science and mathematics is necessary for successful completion of the programme and concludes that early intervention strategies in the areas of academic support and tutoring (in relevant areas) could be developed to increase programme completion rates.

The aim of this study was to determine if there is any significant relationship between students' basic entry qualification into Schools of Nursing and their performance in the final in-school qualifying examinations.

\section{Hypotheses}

1) There is no significant relationship between students entry qualification and students academic performance

2) There is no significant difference between the academic performance of the students who have credit passes in all the basic science subjects and those who do not have credit passes in all the basic sciences subjects.

3) There is no significant difference between the performances of students in the two schools used.

\section{Research Methods}

The descriptive co-relational retrospective research design was used for this study to compare the relationship between two variables under consideration i.e. entry qualification and academic performance.

\section{Population}

The scores of 390 students nurses admitted into the schools of nursing in Enugu State, between 1995 and 1999 were used for the study. The scores were the entry qualifications i.e., the WASC/GCE/SSCE results and their performance results i.e. pre-qualifying final examination results.

\section{Measurement}

The researchers collected data on entry requirements from student's official files in the two schools. Copies of students' credentials are usually kept in their files and they were made available to the researchers after due process of permission and ethical clearance. The raw scores of the pre-qualifying final examination results were also collected from records.

\section{Data Analysis}

The entry qualifications of the students were converted to scores using the stanine scales. This was quantified using the WASC/GCE/SSCE examination grading system of A1 to F9 (see Table 1) which were then calculated and correlated with their performance in the final examination using the Pearson's Correlation Coefficient. Ttest was also used to compare the mean difference between the performance of those who have credit passes in all the science subjects and those who do not have credit passes in all the basic science subjects, and the mean difference in the performance of the students in both schools. 
Table 1. Showing conversion of school grades to scores using stanine scale.

\begin{tabular}{cc}
\hline WASC/GCE/SSCE Grades & Points \\
\hline A1 & 9 \\
A2 & 8 \\
A3 & 7 \\
C4 & 6 \\
C5 & 5 \\
C6 & 4 \\
P7 & 3 \\
P8 & 2 \\
F9 & 1 \\
\hline
\end{tabular}

\section{Results}

\subsection{Hypothesis 1}

There is no significant relationship between students entry qualification and students academic performance. To test this hypothesis, the data generated were analyzed using Pearson product moment correlation (see Table 2).

The result of the analysis $(r=0.48 ; P<0.05)$ indicated that there is a positive relationship between entry qualification and students performance which is statistically significant. The null hypothesis was therefore rejected.

\subsection{Hypothesis 2}

There is no significant difference between the academic performance of the students who had credit passes in all the basic sciences subjects and those who do not have credit passes in all the basic science subjects. To test this hypothesis, the data collected were analyzed using t-test (see Table 3).

The result of the analysis indicated that there is a significant difference between the academic performance of the student that had credit passes in all the basic science subjects and the students who do not have credit passes in all the basic science subjects $(\mathrm{t}=4.20 ; P<0.05)$ The null hypothesis is therefore rejected.

\subsection{Hypothesis 3}

There is no significant difference between the academic performances of the two schools used; the mean scores of both schools were compared using t-test (see Table 4).

The result of this analysis indicated that there is a significant difference between the academic performances of the students in those two schools. $(\mathrm{t}=-7.3 ; P<0.05)$. The null hypothesis is therefore rejected.

\section{Discussion}

The problem statement of the study was to find out the relationship between entry qualification and performance of student nurses in Enugu State, between 1995 and 1999. WASC/GEC/SSCE was used as the entry qualification while the average score at the Hospital Final Examination was used as their performance.

Findings on the first hypothesis indicated a positive linear correlation $(\mathrm{r}=0.48 ; P<0.05)$. This means that performance of students can be predicted with the entry qualification. This means that students' entry requirements correlated with their performance. This agrees with the findings of previous works as reviewed such as Platt et al. (2001) as well as Durotolu, (1994) who both found entry requirements to be predictive of academic achievement. It is also in line with the findings of Ojorinde, (1975), who investigated the predictive validity of the national common Entrance Examination battery. The criterion variable was success in secondary school as measured by the school certificate//GCE examinations. The study concluded that the measure is the best predictor of the criterion measures.

On the second hypothesis, result showed a mean difference of $2.3(\mathrm{t}=4.20 ; P<0.05)$ which indicates that students who have credit passes in all the basic sciences performed better than those who do not have credit passes in all basic science subjects. This result supports the emphasis which has been laid on the entry qualifica- 
Table 2. Pearson correlation between entry qualification and students academic performance $(\mathrm{n}=390)$.

\begin{tabular}{cccc}
\hline No of paired scores $(\mathrm{n})$ & Calculated $\mathrm{r}$ & Critical $\mathrm{r}$ & Level of significance \\
\hline 390 & 0.48 & 0.195 & 0.05 \\
\hline
\end{tabular}

Note: $P<0.05$.

Table 3. Showing difference in the academic performance of the students that have credit passes and their counterparts who do not have credit passes in all the basic sciences subjects $(n=390)$.

\begin{tabular}{ccccccc}
\hline & & & & & \\
Group & $\mathrm{N}$ & $\mathrm{X}$ & $\mathrm{SD}$ & $\begin{array}{c}\text { Calculated } \\
\mathrm{t}\end{array}$ & $\begin{array}{c}\text { Critical } \\
\mathrm{t}\end{array}$ & $\mathrm{P}$ \\
\cline { 2 - 6 } & 112 & 60.5 & 5.2 & 4.20 & 1.96 & $\mathrm{~S}$ \\
\hline $\begin{array}{c}\text { Those with credit passes in all } \\
\text { basic science subjects } \\
\begin{array}{c}\text { Those without credit passes in all } \\
\text { basic science subjects. }\end{array}\end{array}$ & 278 & 58.2 & 4.7 & & \\
\hline
\end{tabular}

Note: $P<0.05$.

Table 4. Showing difference in the mean performance of the students in the schools used in the study $(\mathrm{n}=390)$.

\begin{tabular}{ccccccc}
\hline & & \multicolumn{3}{c}{ Academic Performance } \\
\cline { 2 - 6 } Schools & $\mathrm{n}$ & $\mathrm{X}$ & $\mathrm{SD}$ & Calculated t & $\begin{array}{c}\text { Critical } \\
\mathrm{t}\end{array}$ & -1.96 \\
$\mathrm{~A}$ & 196 & 49.9 & 31.51 & -7.3 & $(\mathrm{P})$ \\
$\mathrm{B}$ & 194 & 13.6 & 13.6 & \\
\hline
\end{tabular}

Note: $P<0.05$.

tion of all the basic sciences for the new cubiculum for the ND/HND programme in nursing. According to Griffiths, Bevil, O'Connor, \& Wieland, (1995), the rigors of the healthcare profession require that professionals have a strong background in science. The basic entry qualification will make the diploma nurses to gain admission into the university with ease and it will help them to move on well with other health sciences students in the faculty.

Findings on the third showed the mean difference of $17.9(\mathrm{t}=-73 ; p<0.05)$, indicating a difference in performance between School A and School B and therefore a rejection of the null hypothesis. This means that school B performed better than school A. Various factors could have affected the students either positively or negatively.

The general implication of this study is nursing faculty members and nursing school administrators should aim at admitting high performing student and that all prospective nursing students should have credit passes in all the basic science subjects as prerequisites for success in the qualifying examination.

\section{Conclusion}

Based on the results and findings, the following conclusions were drawn.

1) When the entry qualification was correlated with the performance, the result showed that there is positive relationship which is statistically significant with a good predictive validity.

2) The finding also showed that the candidates who were admitted with credit passes in all the basic science subjects performed better than those who do not have credit passes in all the basic science subjects.

3) One school performed better than the other and it was statistically significant.

\section{Recommendation}

Based on the findings, the following recommendations are made:

1) Prospective student nurses should possess credit passes in all the basic science subjects before they are admitted into the school of nursing. It will help them to equate themselves with their counter-parts in the health sciences. It will also offer a good background for all the science related courses they will face in future. 
2) High performing prospective students should be targeted for admission to ensure retention and subsequent successful completion.

3) School administrators and nurse educators should evaluate student's performance from time to time in order to remediate areas of laxity.

\section{Limitations of the Study}

It was not possible to lay hands on the data of student's performance in the final professional qualifying examination which was uniform for all the schools in the country, hence the pre qualifying examination results conducted by the different schools to simulate the final examination was used. This constituted an obvious limitation.

Poor record keeping also posed a challenge: one school in the state did not have records for up to five years at the time of study and therefore those tears were not included.

\section{References}

Abdulahi, A. (1983). A Study of the Predictive Value of Joint Admission Matriculation Examination in Selected School Subjects. Journal of Nigerian Educational Research Association, 3, 29.

Alexanders, J., \& Brophy, G. (1997). A Five-Year Study of Graduates’ Performance on NCLEX-RN. Journal of Nursing Education, 36, 443-445.

Alias, M., \& Zain, A. F. M. (2006). Relationship between Entry Qualifications and Performance in Graduate Education. International Education Journal, 7, 371-378. http://iej.com.au371

Croxon, L., \& Maginnis, C. (2006). Total Learning Environment and the Implications for Rural Student Nurse Retention. The Australian Journal of Rural Health, 14, 132-133. http://dx.doi.org/10.1111/j.1440-1584.2006.00776.x

Durotolu, A. O. (1994). Entry Qualification and Periodic Assessment as Predictors of End-of-Semester Performance of the Students of the College of Education Oro. The Nigerian Teachers (Today). A Journal of Teachers Education, 3, $107-115$.

Dienye, E. N. (1991). The Effect of Entry Qualification on Teacher Performance at an In-Service Course. The Nigerian Teacher (Today). A Journal of Teachers Education, 11, 42-48.

Fowles, E. R. (1992). Predictors of Success on NCLEX-RN and within the Nursing Curriculum: Implications for Early Intervention. Journal of Nursing Education, 31, 53-57.

Gbamanja, S. P. T. (1991). Essentials of Cubiculum and Instruction Theory and Practice (2nd ed.). Port Harcourt: Pam Unique.

Glossop, C. (2001). Student Nurse Attrition from Pre-Registration Courses: Investigating Methodological Issues. Nurse Education Today, 21, 170-180. http://dx.doi.org/10.1054/nedt.2000.0525

Griffiths, M. J., Bevil, C. A., O’Connor, P. C., \& Wieland, D. M. (1995). Anatomy and Physiology as a Predictor of Success in Baccalaureate Nursing Students. Journal of Nursing Education, 34, 61-66.

Habley, W. R., \& McClanahan, R. (2004). What Works in Student Retention? Two-year public colleges. Iowa City, IA: ACT, Inc.

Hossler, D. (2005). Managing Student Retention: Is the Glass Half Full, Half Empty, or Simply Empty? College and University Journal, 81, 11-14.

Igbinosun, P. E. (1996). Issues in Nursing in Nigeria. Lagos: Amfitop Book Company.

Jimoh, S. A., \& Durotolu, A. O. (1988). Relationship between Entry Qualification and Performance of NCE Students in Education Courses. A Case Study of the College of Education, Oro. Oro Journal of Educational Students, 3, 39-76.

Kasworm, C. E., \& Pike, G. R. (1994). Adult Undergraduate Students: Evaluating the Appropriateness of a Traditional Model of Academic Performance. Research in Higher Education, 35, 689-695. http://dx.doi.org/10.1007/BF02497082

Lengacher, C. A., \& Keller, R. (1990). Academic Predictors of Success on the NCLEX-RN Examination for Associate Degree Nursing Students. Journal of Nursing Education, 29, 163-169.

Mckenzie, B., \& Bancroft, A. (2008). Predictors of Academic Success in a Career-Ladder Nursing Program at Hocking College. Ph.D. Dissertation, Department of Counselling and Higher Education.

Ojorinde, A. (1975). Predicting Academic Success in School Certification Examination from National Common Entrance Examination Scores. Unpublished Master's Thesis, Ile-Ife: Obafemi Anolowo University.

Platt, L. S., Turocy, P. S., \& McGlumphy, B. E. (2001). Preadmission Criteria as Predictors of Academic Success in EntryLevel Athletic Training and Other Allied Health Educational Programs. Journal of Athletic Training, 36, 141-144. 
Ramsburg, L. (2007). Strive for Success: A Successful Retention Program for Associate of Science in Nursing Students. Teaching and Learning in Nursing, 2, 12-16. http://dx.doi.org/10.1016/j.teln.2006.10.005

Sensitization/Implementation Workshop for ND/HND Nursing Programme (2002). Nursing \& Midwifery Council of Nigeria News Letter (7th ed.). 